\section{What Determines the Response to Landiolol?}

\section{To the Editor:}

We read the article by Oka et al stating the difference in landiolol response between atrial fibrillation $(\mathrm{AF})$ and atrial flutter (AFI)/atrial tachycardia (AT) with great interest. ${ }^{1}$ Because AF/AFl/AT sometimes provokes critical hemodynamic deterioration, particularly among advanced heart failure patients, prompt and appropriate rate control is mandatory for such patients. ${ }^{2,3}$ Therefore, their finding is important for the prediction of landiolol responders. We have several concerns to be clarified.

First, reduced left ventricular ejection fraction (LVEF) might still remain an important predictor of non-response to landiolol. Wada and colleagues reported that lower LVEF was associated with poor response to landiolol and suggested that landiolol may not be recommended for heart failure patients with extremely low LVEF $(<25 \%) .{ }^{4}$ Although the multiple logistic regression analysis (Table 4) demonstrated that lower LVEF was not associated with non-response to landiolol, 4 variables in the multivariate model might be too much, considering the small sample size, to obtain reliable statistical results. Also, the AFl/AT group tended to have lower LVEF compared with the AF group (Table 1). Statistical power might be insufficient to detect significant difference in the LVEF between groups because of the small sample size. The authors described that $3(25 \%)$ patients in the AFI/AT group discontinued landiolol because of hypotension as well as uncontrolled heart rate. Those 3 patients might have had reduced LVEF and could not tolerate landiolol therapy.

Our second concern is about the mechanism of landiolol therapy. It is hypothesized in the discussion section that the major action of landiolol is prolongation of the effective refractory period of the AV node. However, some AT is also caused by enhanced local abnormal automaticity. $\beta 1$-blockade would be also efficient against such a mechanism, but we have no answers on whether the landiolol response differs according to the arrhythmia mechanism. If any electrophysiological studies were performed during the arrhythmias, the mechanism of landiolol response may be clarified in more detail. Of note, there might be a risk of hemodynamic deterioration when performing such studies in patients with advanced heart failure.

\section{Disclosures}

The authors have no conflicts of interest related to the manuscript.

\section{Acknowledgment}

None.

\section{References}

1. Oka E, Iwasaki Y, Maru E, Fujimoto Y, Ito-Hagiwara K, Hayashi $\mathrm{H}$, et al. Differential effectiveness of landiolol between atrial fibrillation and atrial flutter/atrial tachycardia patients with left ventricular dysfunction. Circ J 2019; 83: 793-800.

2. Nitta D, Kinugawa K. Imamura T, Endo M, Amiya E, Inaba T, et al. An experience of landiolol use for an advanced heart failure patient with severe hypotension. Int Heart J 2015; 56: 564-567.

3. Saito A, Amiya E, Hatano M, Hosoya Y, Maki H, Nitta D, et al. Newly developed atrial fibrillation progresses to a more severe INTERMACS score in a patient with advanced heart failure due to dilated cardiomyopathy. Clin Case Rep 2017; 5: 2028-2033.

4. Wada Y, Aiba T, Tsujita Y, Itoh H, Wada M, Nakajima I, et al. Practical applicability of landiolol, an ultra-short-acting $\beta 1$-selective blocker, for rapid atrial and ventricular tachyarrhythmias with left ventricular dysfunction. J Arrhythm 2016; 32: 82-88.

$$
\begin{array}{r}
\text { Daisuke Nitta, MD, PhD } \\
\text { Teruhiko Imamura, MD, PhD } \\
\text { Division of Cardiology, } \\
\text { Department of Medicine, } \\
\text { The University of Chicago Medicine, } \\
\text { Chicago, IL, USA }
\end{array}
$$

Received March 18, 2019; accepted March 19, 2019; J-STAGE Advance Publication released online June 11, 2019

Mailing address: Teruhiko Imamura, MD, PhD, Division of Cardiology, Department of Medicine, The University of Chicago Medicine, 5841 S Maryland Ave, Chicago, IL 60637, USA. E-mail: t.med.timamura@medicine.bsd.uchicago.edu ISSN-1346-9843 All rights are reserved to the Japanese Circulation Society. For permissions, please e-mail: cj@j-circ.or.jp 